\title{
SASOL SYNFUELS AIR QUALITY MONITORING NETWORK
}

\author{
Gerrit Kornelius, Owen Pretorius, Sasha Nulliah
}

Sasol Synfuels (Pty) Limited

\section{INTRODUCTION}

Air Quality measurements near Sasol Secunda facility have been carried out for more that a decade. The network was recently expanded to have three additional stations on a regional scale (80 - $100 \mathrm{~km}$ from Secunda), mainly to determine the effect that a sulphur recovery plant upgrade that was started in 2002 will have an ambient concentration of sulphur species.

The criteria pollutants, classically recognized by regulatory agencies as detrimental to health on short-term exposure. These include sulphur dioxide, the nitrogen oxides, ozone and particulate matter. On the latter, in the absence of a formal decision by SA authorities, we have decided to measure PM 2.5 (particulate matter smaller than 2.5 micron), as there is international consensus that this measurement rather has a more direct correlation with impact on health than total particulates or even PM 10. As hydrogen sulphide emissions at this stage are a concern for Synfuels and a number of engineering developments are taking place in this area, hydrogen sulphide concentration is included in this measurement group.

Hazardous air pollutants, with a longer-term but less well-defined health impact. In this category, Synfuels emits a variety of hydrocarbons. Ad-hoc measurements of community exposure started three years ago although occupational hygiene measurements for hydrocarbon exposure have been carried out for a number of years. Based on the ad-hoc measurement results, regular fence-line measurements using passive samples was started two years ago. These indicated levels of benzene, toluene and the xylenes that are measurable but no cause for concern against the commonly used exposure standards. In addition, Synfuels takes part in the hydrocarbon measurement programme co-ordinated by Sastech Research and Development. This will allow the measurement of additional hydrocarbon species. Results are still of a preliminary nature and are reported on in a separate paper.
Measurement of PM 2.5 has been carried out in the eMbalenhle area for the past four winters in connections with the NOVA project for domestic smoke reduction. Measurements are carried out using standard gravimetric apparatus and methods. Results of the project have been fully reported on elsewhere (SA Clean Air Journal, Vol 10 no. 4, Nov. 1999). In summary, average concentration was approximately 300 microgram per cubic meter in winter and 100 microgram per cubic meter in summer, compared to an EPA guideline of 65 microgram per cubic meter. Winter concentrations on average have been reduced by $20 \%$ in the first year by introducing smoke reduction methods to approximately half of the eMbalenhle population. Preliminary results on the second year, when the entire population has been exposed, indicates a further approximate $15 \%$ reduction.

\section{RESULTS}

Detailed results are presented below for the criteria pollutant measurements. Ambient air quality monitoring around Secunda is done in two "rings", a local one and a regional one.

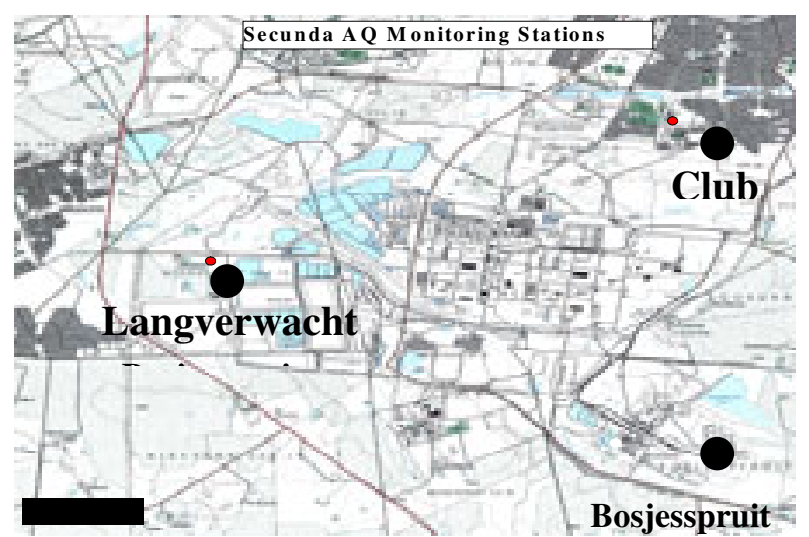

Figure 1: Position of local Air Quality Monitoring Laboratories 


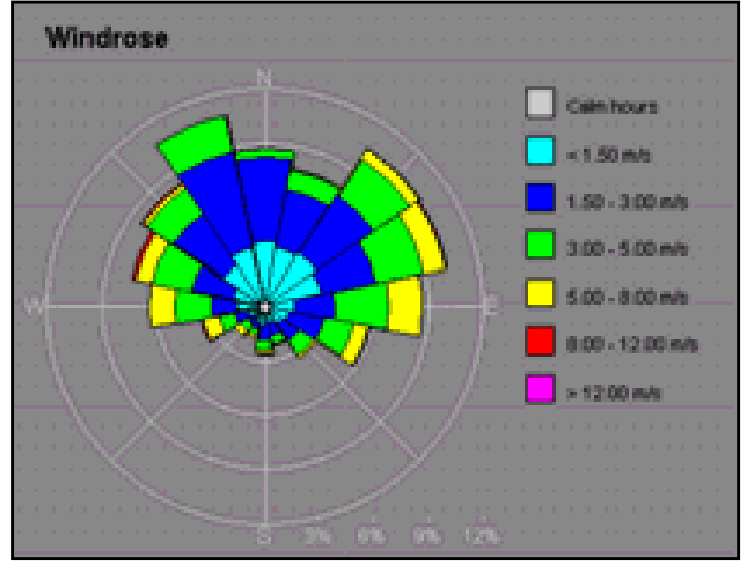

Figure 2: Wind Rose Period January - December 2002

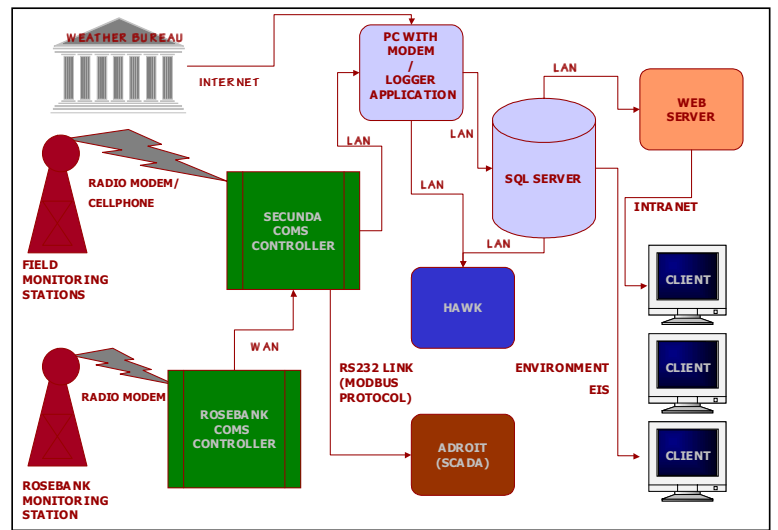

Figure 3: Air Quality Communication System Monitoring Network

Position of local network stations is, based on location of residential areas (Secunda and eMbalenhle) and prevailing North-westerly wind direction (Bosjesspruit) as indicated in fig 1 and 2. Ambient air quality measurements are recorded every 2.5 seconds averaged to $15 \mathrm{~min}$, hourly, daily and monthly data points for ozone, oxides of nitrogen, nitrogen oxide, nitrogen dioxide, sulphur dioxide, hydrogen sulphide and Particulates (PM 2.5). Measurement of meteorological conditions also stored in database: Wind speed, wind direction, ambient temperature, atmospheric pressure, rainfall, relative humidity, solar radiation and wet bulb temperature. The system is accredited to ISO 17025 to ensure validity of data and procedure of operation.

\section{Local results}

The graphs below indicate percentage frequency of ambient concentration levels of Hydrogen Sulphide by concentration classes, with the bars giving frequency per concentration interval and the line cumulative frequency.
The objective is to stay below the odour threshold level $(5 \mathrm{ppb})$ for $99 \%$ of the time for all receptors. This was agreed with the Department of Environmental Affairs as constituting an interim "ho nuisance" level of impact. The low conformance level indicates the necessity for the sulphur recovery plant upgrade that is presently in progress.

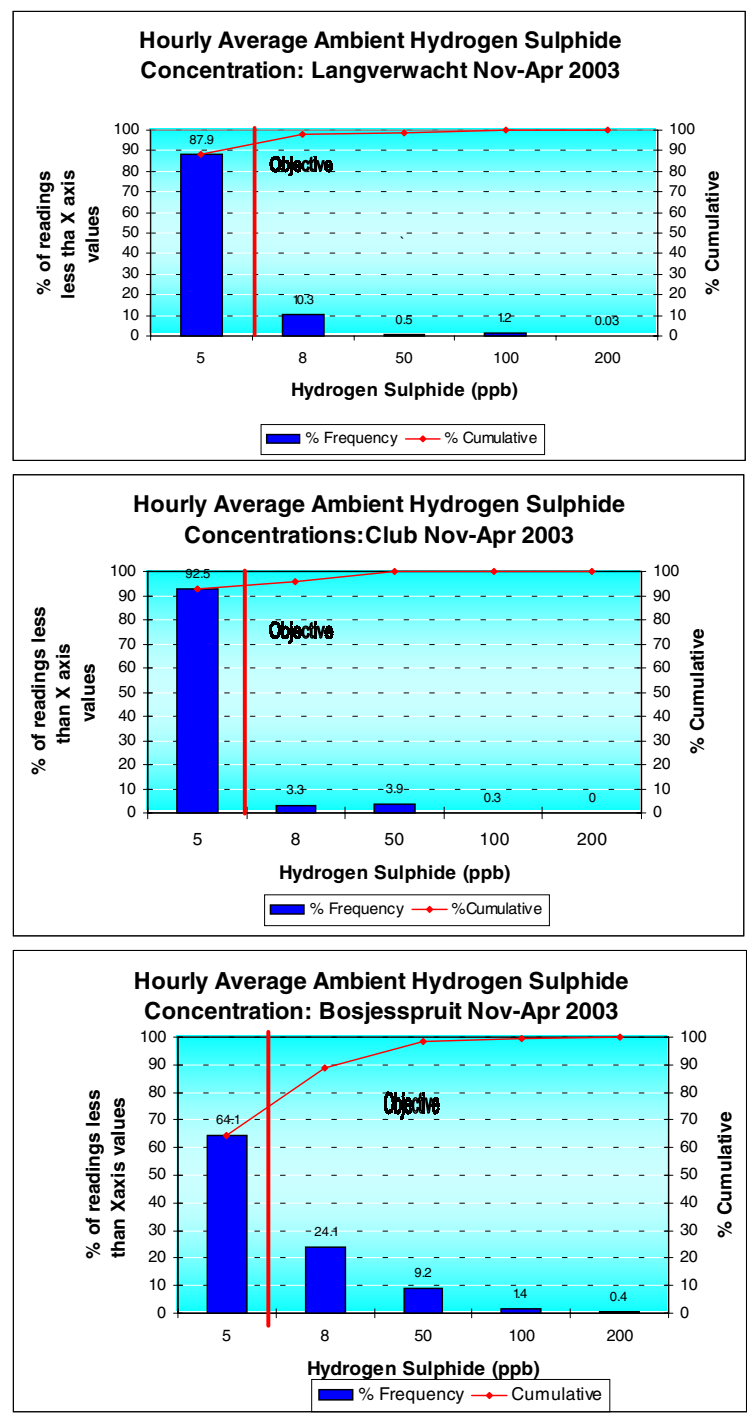

The following graphs indicate percentage frequency of ambient concentrations of Sulphur Dioxide. The objective is $100 \%$ conformance to a daily average of $48 \mathrm{ppb}$, the guideline set by the World Health Organization (WHO). This objective is achieved, although with limited room for additional emissions. 

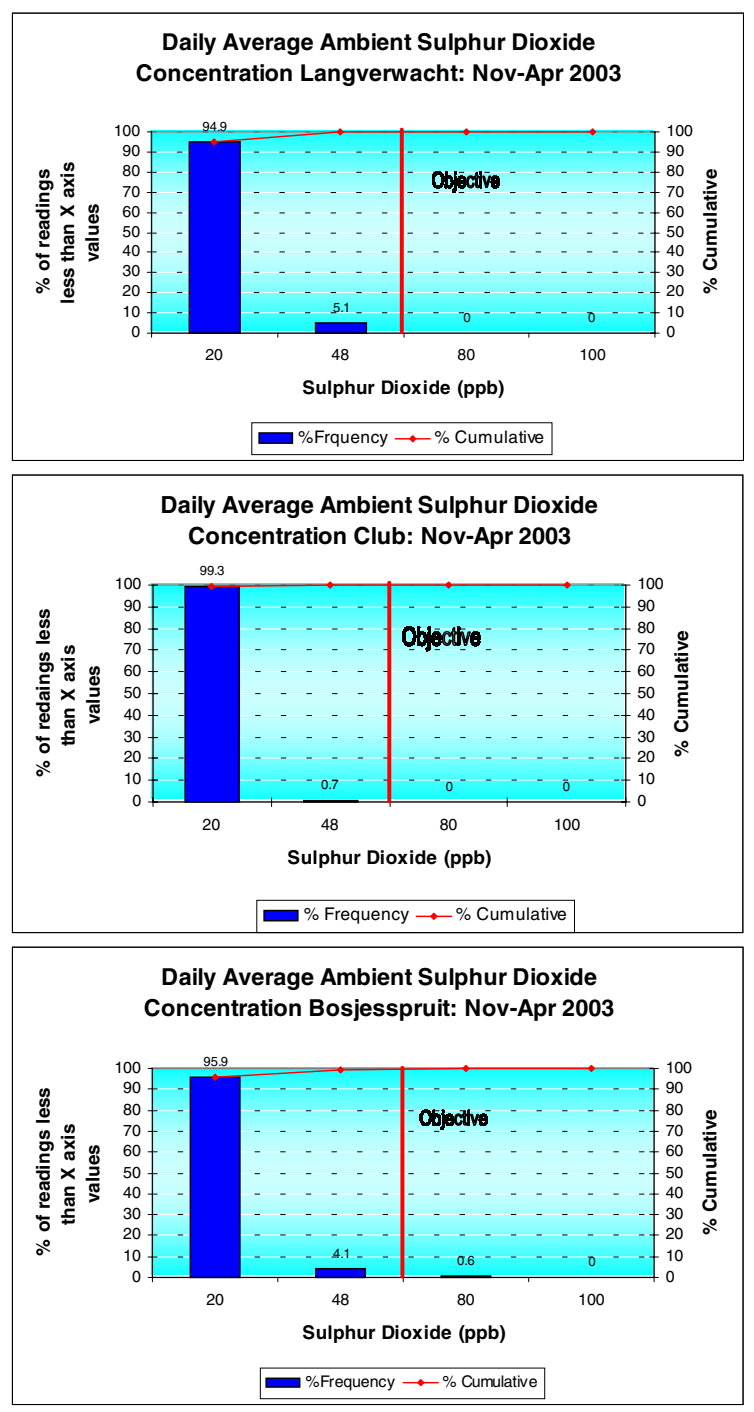

The graphs that follow indicate percentage frequency of ambient concentrations of ozone. The objective is to achieve $100 \%$ below an hourly average of $120 \mathrm{ppb}$, the guideline set by the World Health Organization (WHO), which is comfortably achieved.

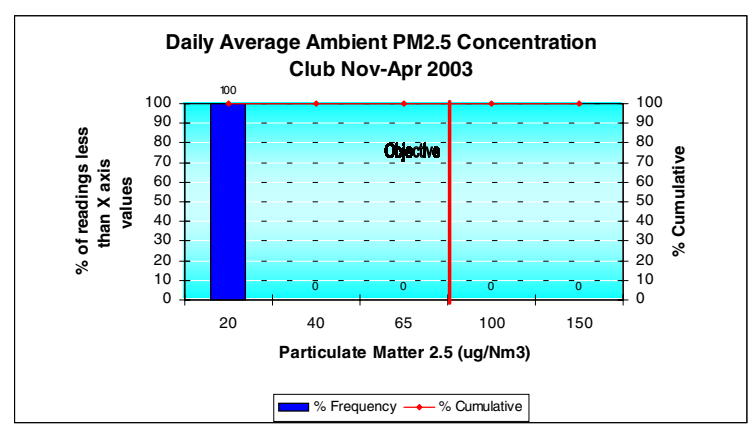

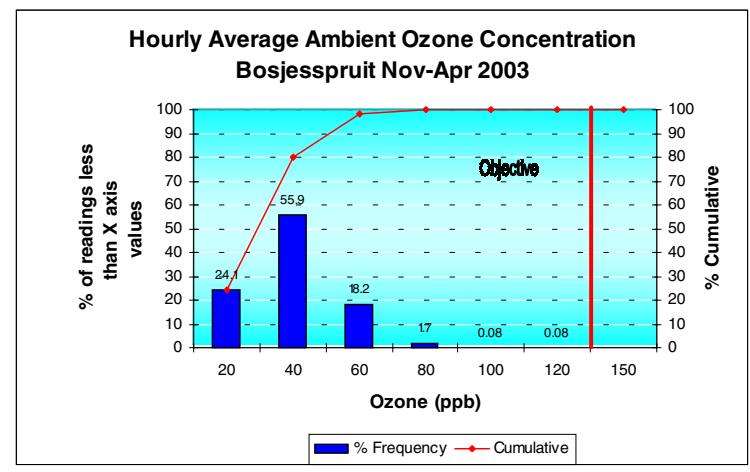

The following graphs indicate percentage frequency of ambient concentration of PM2.5. The objective is to achieve $100 \%$ below a daily average of $65 \mu \mathrm{g} / \mathrm{Nm}^{3}$, this is the guideline set by the US Environmental Protection Agency.

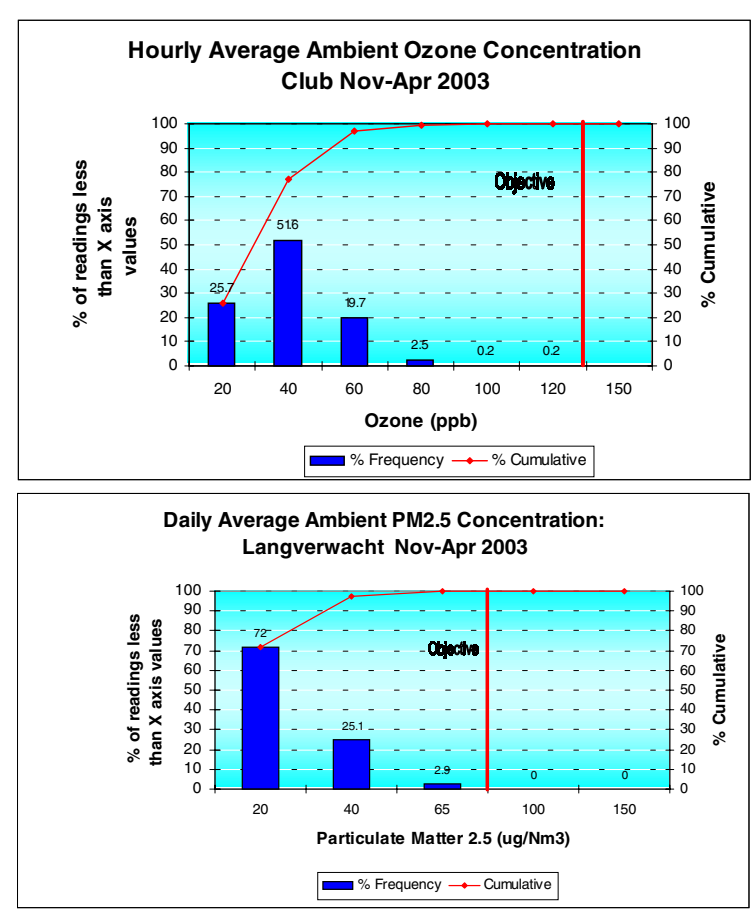


The main purpose of the regional network (or $2^{\text {nd }}$ ring) is to determine community exposure to hydrogen sulphide, which is a Synfuels-specific pollutant at this scale. (See Fig. 4)

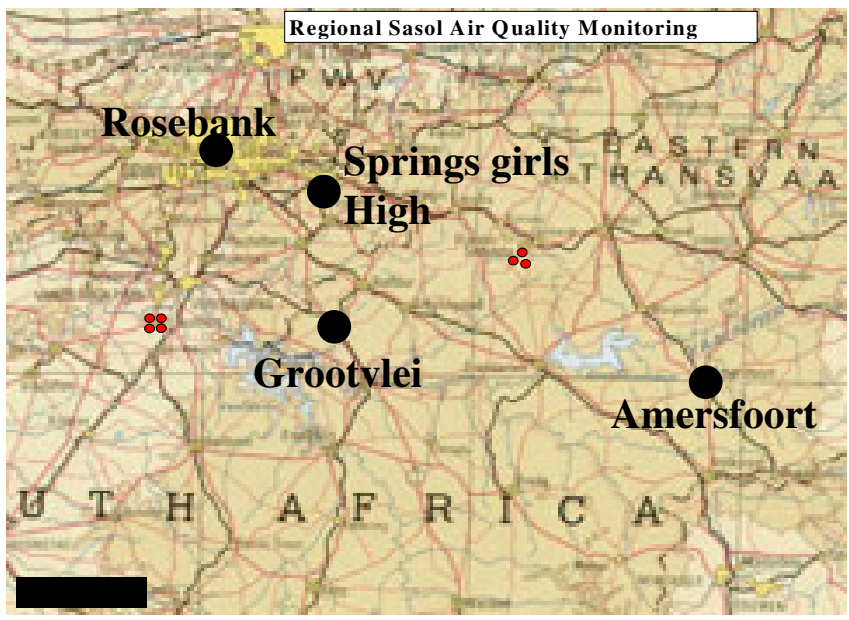

Figure 4: Position of regional air quality station

\section{Regional results}

The graphs below indicate the percentage frequency of ambient concentration levels of Hydrogen Sulphide.

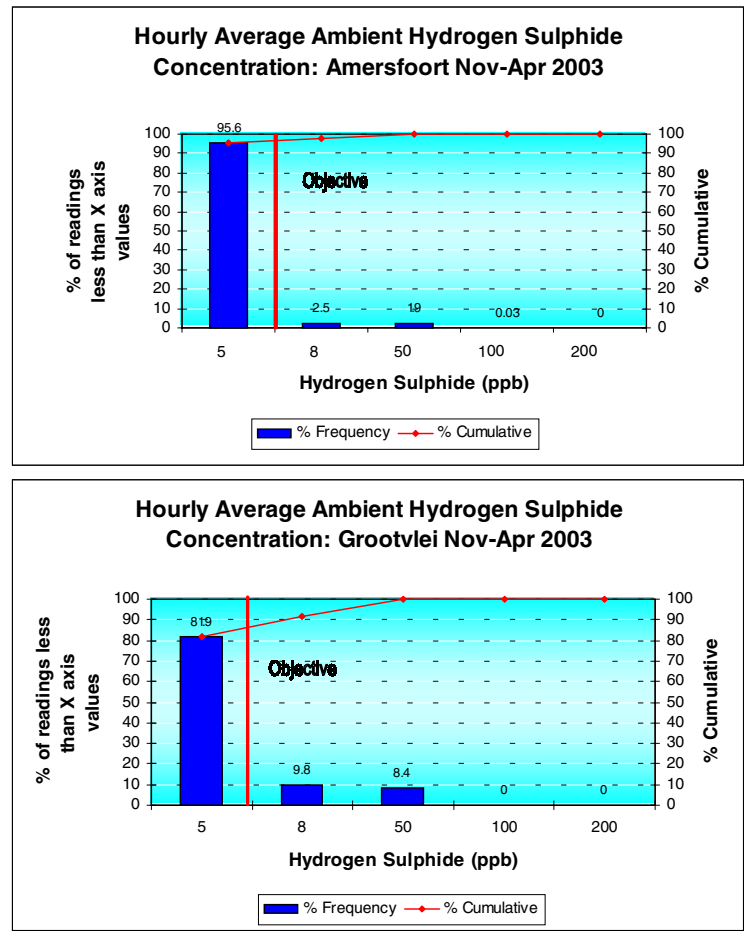

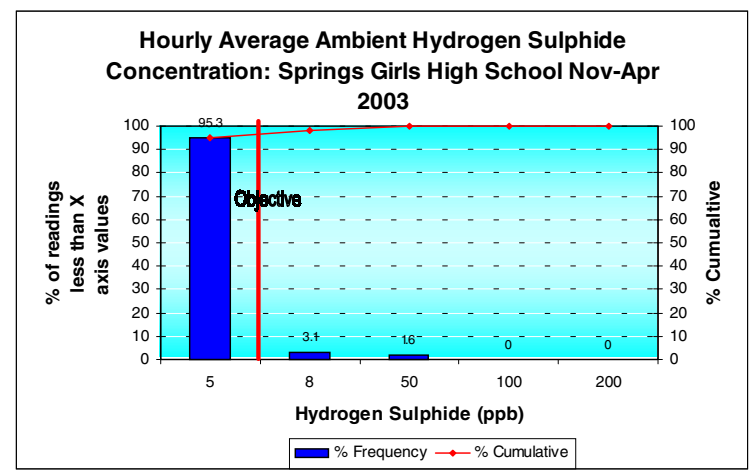

\section{Hydrogen disulphide conc. at Grootvlei Monitoring Station}

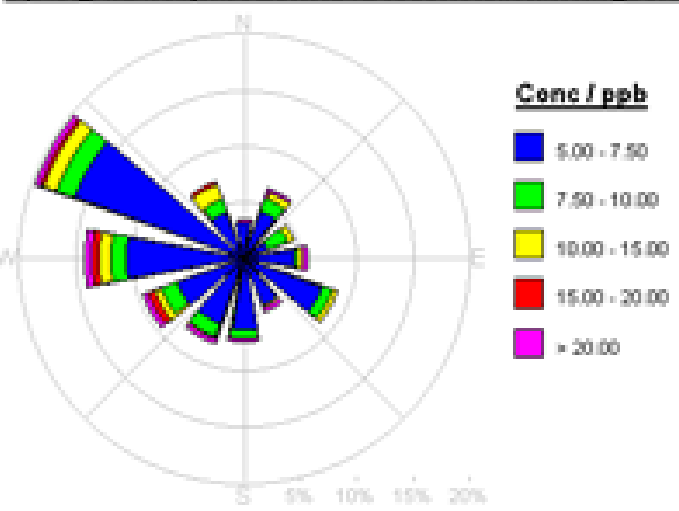

Looking at the "pollution roses" only for those concentration values exceeding the odour threshold, it is clear that Grootvlei (top) is influenced much more by sources in the Vaal area than by the Secunda plumes.

The results for Springs are similar, with an additional smaller source to the north of the station, probably the local sewage works

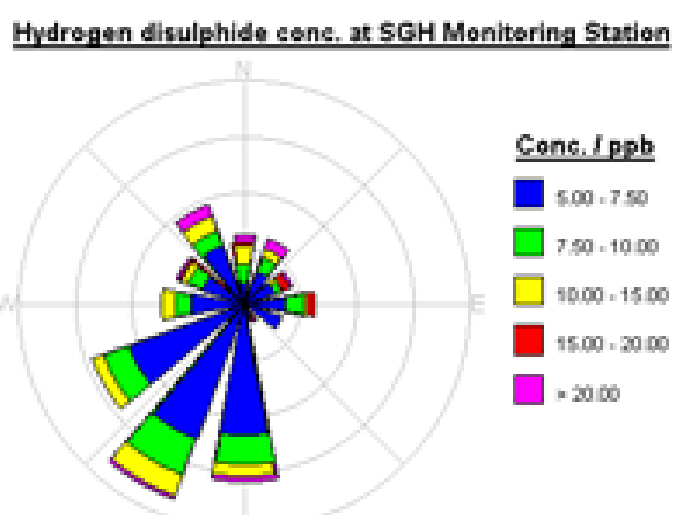


The graphs below indicate the percentage frequency of ambient concentration levels of Sulphur Dioxide.

\section{PRELIMINARY ANALYSIS POLLUTION ROSES}

Sulphur dioxide cenc. at Bosiesspruit Monitoring Station

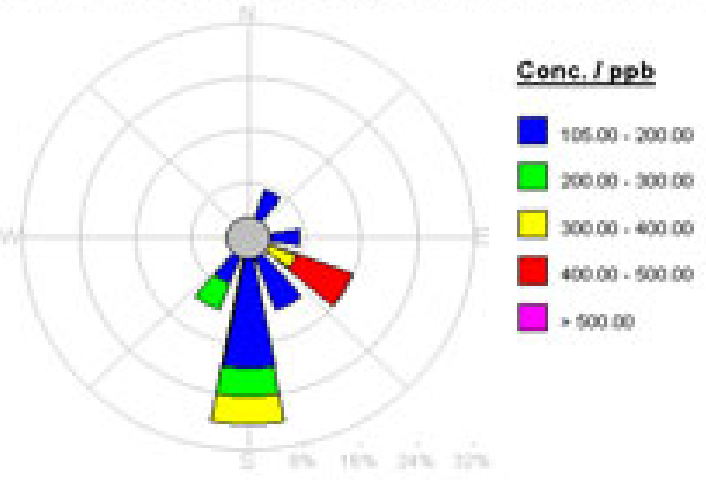

A "pollution rose" analysis for the local $\mathrm{SO}_{2}$ stations show the phenomenon that distant sources (in this case probably Tutuka) have a much bigger influence on local ground-level concentrations that the local high-level sources, which is at $300 \mathrm{~m}$ too high to influence a station approximately $5 \mathrm{~km}$ from the stack.

\section{Sulphur dioxide conc. at SGH Monitoring Station}

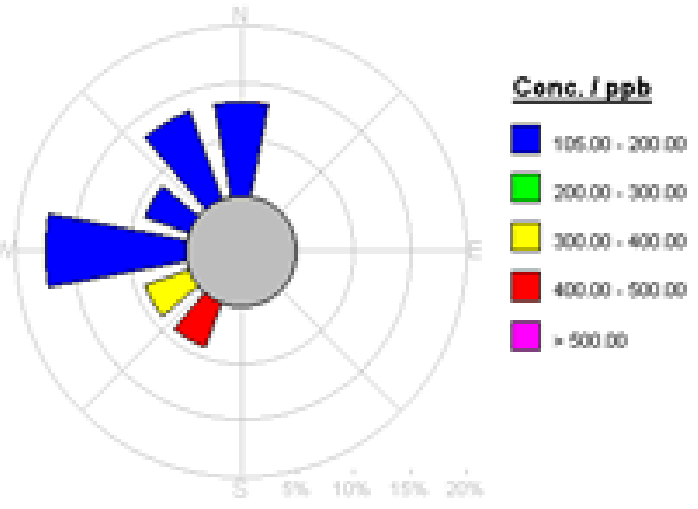

At Springs, it seems that the influence of local low-level source is more pronounced that that of the sources in the Vaal area, while the Eastern Mpumalanga sources cause no exceedence of the hourly standard at all.

\section{Ozone conc. at Bosjesspruit Monitoring Station}

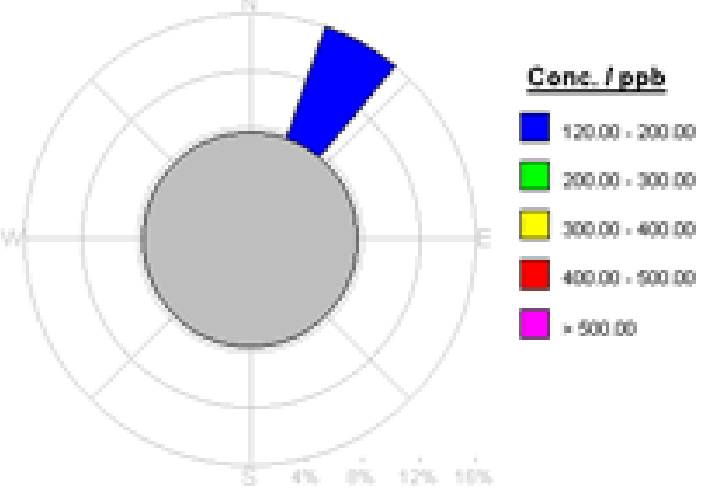


For ozone, the picture is much less clear. When plotting exceedences of the hourly WHO guideline only local traffic or sources as far away as Middelburg/Witbank might be implicated.

\section{Ozone conc. at Amersfoert Monitoring Station}

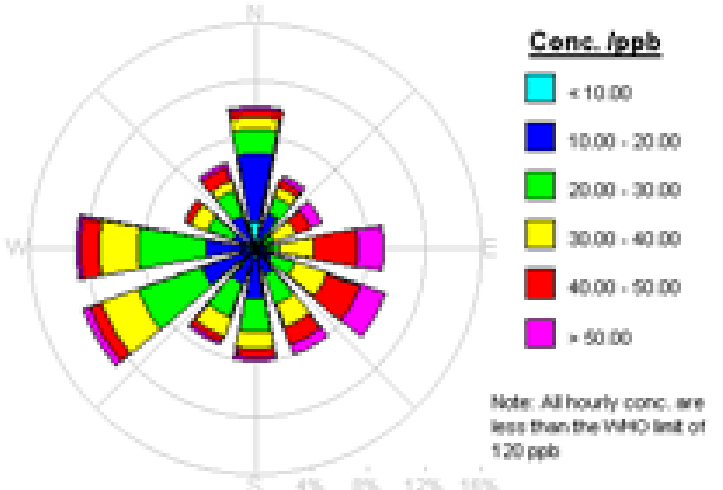

Plotting the full spectrum at Amersfoort, the pattern is even more confusing and clearly further analysis, taking diurnal patterns into account, is required. 